\section{(2) OPEN ACCESS}

\title{
Integrated safety analysis of filgotinib in patients with moderately to severely active rheumatoid arthritis receiving treatment over a median of 1.6 years
}

\author{
Kevin L Winthrop (D) ,' Yoshiya Tanaka (D) , ${ }^{2}$ Tsutomu Takeuchi (D) , ${ }^{3}$ Alan Kivitz, ${ }^{4}$ \\ Franziska Matzkies, ${ }^{5}$ Mark C Genovese (D) , ${ }^{5}$ Deyuan Jiang, ${ }^{5}$ Kun Chen, ${ }^{5}$ \\ Beatrix Bartok ${ }^{5}$ Angelika Jahreis, ${ }^{5}$ Robin Besuyen, ${ }^{6}$ Gerd R Burmester (I) , \\ Jacques-Eric Gottenberg (iD ${ }^{8}$
}

\begin{abstract}
Handling editor Josef S Smolen

- Additional supplemental material is published online only. To view, please visit the journal online (http://dx.doi. org/10.1136/annrheumdis2021-221051)
\end{abstract}

For numbered affiliations see end of article.

\section{Correspondence to}

Dr Kevin L Winthrop, Oregon Health \& Science University, Portland, OR 97239, USA; winthrop@ohsu.edu

Received 22 June 2021 Accepted 18 September 2021 Published Online First 5 November 202

\section{Check for updates}

(C) Author(s) (or their employer(s)) 2022. Re-use permitted under CC BY-NC. No commercial re-use. See rights and permissions. Published by BMJ.

To cite: Winthrop $\mathrm{KL}$, Tanaka Y, Takeuchi T, et al. Ann Rheum Dis 2022:81:184-192.

\section{ABSTRACT}

Objective To characterise safety of the Janus kinase-1 preferential inhibitor filgotinib in patients with moderately to severely active rheumatoid arthritis. Methods Data were integrated from seven trials (NCT01668641, NCT01894516, NCT02889796, NCT02873936, NCT02886728, NCT02065700, NCT03025308). Results are from placebo (PBO)controlled (through week (W)12) and long-term, as treated (all available data for patients receiving $\geq 1$ dose filgotinib 200 (FIL200) or $100 \mathrm{mg}$ (FIL100) daily) datasets. We calculated exposure-adjusted incidence rates (EAIRs)/100 patient-years filgotinib exposure (100PYE) for treatment-emergent adverse events (TEAEs).

Results 3691 patients received filgotinib for 6080.7 PYE (median 1.6, maximum 5.6years). During the PBO-controlled period, TEAEs, including those of grade $\geq 3$, occurred at comparable rates with filgotinib or PBO; long-term EAIRs of TEAEs grade $\geq 3$ were 6.4 and 7.6/100PYE for FIL200 and FIL100. EAIRs for deaths were 0.6/100PYE for FIL200, FIL100 and PBO; long-term EAIRs were 0.5 and 0.3/100PYE for FIL200 and FIL100. EAIRs for serious infection were 3.9, 3.3 and 2.4/100PYE for FIL200, FIL100 and PBO; long-term EAIRs were 1.6 and 3.1/100PYE for FIL200 and FIL100. EAIRs for herpes zoster were 0.6, 1.1, and 1.1/100PYE for FIL200, FIL100 and PBO; long-term EAIRs were 1.8 and 1.1/100PYE for FIL200 and FIL100. EAIRs for major adverse cardiovascular events were 0,1.7 and 1.1/100PYE for FIL200, FIL100 and PBO; long-term EAIRs were 0.4 and 0.6/100PYE for FIL200 and FIL100. No venous thromboembolism occurred during the PBO-controlled period; long-term EAIRs were 0.2 and 0/100PYE for FIL200 and FIL100.

Conclusions Over a median of 1.6 and maximum of 5.6 years of exposure, safety/tolerability of FIL200 and FIL100 were similar, with a lower incidence of infections with FIL200 among the long-term, as-treated dataset.

\section{INTRODUCTION}

The oral, Janus kinase-1 (JAK1) preferential inhibitor filgotinib has demonstrated efficacy in rheumatoid arthritis (RA) in phase 2 and 3 trials up to 52 weeks. ${ }^{1-5}$ Treatment with filgotinib 200 and $100 \mathrm{mg}$

\section{Key messages}

What is already known about this subject?

- Filgotinib is an oral, preferential Janus kinase-1 inhibitor approved in Europe and Japan for treatment of rheumatoid arthritis (RA).

- In previous clinical trials, filgotinib treatment resulted in improvement in RA signs and symptoms, improvement in physical function, reduced radiographic progression, and improvement in quality of life for patients across the spectrum, from methotrexate-naïve to biologic-refractory RA.

- Filgotinib was generally well tolerated in previous trials and had safety similar to active comparators methotrexate and adalimumab up to 52 weeks.

What does this study add?

- This integrated analysis of safety data from seven clinical trials characterises both the shortterm safety compared with placebo (PBO) for 777 and 788 patients receiving filgotinib 200 and $100 \mathrm{mg}$ and long-term safety of filgotinib 200 and $100 \mathrm{mg}$ in patients with RA exposed for 4047.7 and 2032.9 patient-years (median 1.6 and 1.3 years; maximum 5.6 and 4.7 years).

- Overall, both filgotinib 200 and 100 mg were generally well tolerated. Proportions of patients treated with filgotinib 200 and $100 \mathrm{mg}$ who developed infections and serious infections were higher versus PBO. Opportunistic infections, herpes zoster infections, major adverse cardiac events, and venous thromboembolism were infrequently reported. Longer-term study of filgotinib will further elucidate this safety profile. 
Key messages

\section{How might this impact on clinical practice or future developments?}

- This integrated analysis of PBO-controlled and as-treated extension-study datasets describes the safety of filgotinib as treatment of RA.

- Over a median of 1.6 and maximum of 5.6 years of exposure, safety/tolerability of filgotinib 200 and $100 \mathrm{mg}$ were similar, with a lower incidence of infections with filgotinib $200 \mathrm{mg}$ among the long-term, as-treated dataset.

3 trials. $^{45}$ Most events occurred in similar proportions across treatments. ${ }^{1-5}$

It has been hypothesised that selectivity for JAK1 may preserve the efficacy benefit seen with less selective JAK inhibitors, while limiting the JAK2- and JAK3-mediated safety and tolerability concerns. ${ }^{6}$ Based on a study of in vitro cellular assays and clinical pharmacokinetics of filgotinib, baricitinib, tofacitinib and upadacitinib, filgotinib demonstrated reduced JAK2 and JAK3 activity while maintaining comparable inhibition of JAK1. However, the clinical relevance of JAK selectivity remains unclear. ${ }^{6}$

Here, we use an integrated analysis across seven trials, including long-term extensions (LTEs), to evaluate the safety of filgotinib among patients with RA treated for a median of 1.6 (and up to 5.6) years, with attention to adverse events of special interest (AESIs) with JAK inhibition.

\section{METHODS}

\section{Study designs}

Patient-level data were integrated from two phase 2 (NCT01668641, NCT01894516), three phase 3 (NCT02889796, NCT02873936, NCT02886728) and phases 2 and 3 LTE trials (NCT02065700, NCT03025308) (table 1). Data from patients receiving monotherapy and concomitant conventional synthetic disease-modifying antirheumatic drugs
(csDMARDs) were combined per filgotinib dose. Trials are summarised in online supplemental methods, and the phase 3 LTE protocol is available as supplemental file $2 \cdot{ }^{1-5} 7$ All data from patients receiving filgotinib 200 or $100 \mathrm{mg}$ once a day or placebo from completed trials were included. Data from ongoing phase 2 and 3 LTEs were included through 26 April 2019 and 16 September 2019.

Eligible patients were aged $\geq 18$ years with a diagnosis of RA per European League Against Rheumatism/American College of Rheumatology 2010 criteria. $^{8}$ Eligible patients were to have swollen and tender joint counts $\geq 6$ and, depending on the study, either documented erosions or elevated serum $\mathrm{C}$ reactive protein (CRP) ${ }^{1-5}$ Exclusion criteria included recent or active infections, major adverse cardiovascular events (MACE) within 6 months prior to screening, and specified abnormal laboratory results at screening. ${ }^{1-5}$ Interruption of study drug was to be considered for any patient who developed an infection during the studies; those with specific laboratory abnormalities (eg, sequential elevations of aspartase aminotransferase or alanine aminotransferase $>3 \times$ the upper limit of normal with either elevated bilirubin or with symptoms of hepatic injury) were to have study drug discontinued. The protocols for the phase 2 studies required study drug discontinuation for any QuantiFERON (QF) tuberculosis (TB) test positivity during the study, independent of clinical diagnosis. Also, in the phase 2 trials only, lymphopaenia (two sequential lymphocyte counts $<500 / \mathrm{mm}^{3}$ ) and elevated creatinine (two sequential increases in serum creatinine $>50 \%$ over the average of screening and baseline values) were criteria for study drug discontinuation. In the phase 3 studies, drug interruption was required per local standard of care for QF TB-positive tests and newly diagnosed latent TB.

\section{Patient and public involvement}

Patients were not involved in research design, conduct or reporting. Patients were recruited by individual sites and provided written, informed consent.

Table 1 Key features of filgotinib RA phases 2 and 3 studies

\begin{tabular}{|c|c|c|c|c|c|c|}
\hline & \multicolumn{3}{|c|}{ Required background medication } & \multicolumn{2}{|c|}{ Control } & \multirow{2}{*}{$\begin{array}{l}\text { Protocol-defined rerandomisation } \\
\text { to FIL }\end{array}$} \\
\hline & None & MTX & csDMARD(s) & PBO & Active comparator & \\
\hline \multicolumn{7}{|l|}{ Phase 3 studies } \\
\hline $\begin{array}{l}\text { FINCH } 1 \\
\text { NCT02889796 }\end{array}$ & & $x$ & & 24 weeks & 52 weeks (ADA) & PBO patients at week 24 \\
\hline $\begin{array}{l}\text { FINCH } 2 \\
\text { NCT02873936 }\end{array}$ & & & $\mathrm{X}$ & 24 weeks & & \\
\hline $\begin{array}{l}\text { FINCH 3* } \\
\text { NCT02886728 }\end{array}$ & $x$ & & & NA & 52 weeks (MTX) & \\
\hline $\begin{array}{l}\text { FINCH } 4 \text { (LTE) } \\
\text { NCT03025308 }\end{array}$ & $x+$ & & & NA & & At study entry \\
\hline \multicolumn{7}{|l|}{ Phase 2 Studies } \\
\hline $\begin{array}{l}\text { DARWIN } 1 \\
\text { NCT01668641 }\end{array}$ & & $x$ & & 24 weeks & & Non-responders at week 12 \\
\hline $\begin{array}{l}\text { DARWIN } 2 \\
\text { NCT01894516 }\end{array}$ & $x$ & & & 12 weeks & & $\begin{array}{l}\text { PBO patients and nonresponders at } \\
\text { week } 12\end{array}$ \\
\hline $\begin{array}{l}\text { DARWIN } 3 \text { (LTE) } \\
\text { NCT02065700 }\end{array}$ & $X \S$ & & & NA & & At study entryף \\
\hline \multicolumn{7}{|c|}{$\begin{array}{l}\text { *In addition to filgotinib } 200 \mathrm{mg}+\mathrm{MTX} \text { and filgotinib } 100 \mathrm{mg}+\mathrm{MTX} \text {, this trial included a filgotinib } 200 \mathrm{mg} \text { monotherapy treatment arm. } \\
\text { †Patients continued to receive parent study protocol-approved background medication; patients in FINCH } 3 \text { receiving MTX discontinued on enrolment in FINCH } 4 . \\
\text { ¥All patients who received FIL at the time of completion of parent study continued to receive blinded FIL dose (100 mg once a day or } 200 \mathrm{mg} \text { once a day). Patients who received ADA, PBO or MTX monotherapy, or who } \\
\text { completed FINCH } 2 \text { on standard of care, were rerandomised at LTE entry to receive either FIL } 100 \mathrm{mg} \text { or FIL } 200 \mathrm{mg} \text {. Patients from FINCH } 1 \text { and FINCH } 3 \text { who completed parent study on standard of care were not eligible. } \\
\text { \$Patients were permitted to restart background MTX therapy if deemed necessary by the investigator. } \\
\text { १Patients who received FIL } 200 \mathrm{mg} \text { once a day or FIL } 100 \mathrm{mg} \text { two times per day at the time of completion of parent study continued to receive the same FIL dose in the LTE study. Patients who received FIL } 25 \mathrm{mg} \text { two } \\
\text { times per day, FIL } 50 \mathrm{mg} \text { once a day, FIL } 50 \mathrm{mg} \text { two times per day or FIL } 100 \mathrm{mg} \text { at the time of completion of parent study were assigned either FIL } 200 \mathrm{mg} \text { once a day or FIL } 100 \mathrm{mg} \text { two times per day at LTE entry. } \\
\text { Patients who received PBO at the time of completion of parent study were rerandomised at LTE entry to receive either FIL } 200 \mathrm{mg} \text { once a day or FIL } 100 \mathrm{mg} \text { two times per day. In the USA, dosing in male subjects was } \\
\text { restricted to FIL } 100 \mathrm{mg} \text { once a day. } \\
\text { ADA, adalimumab; csDMARD, conventional synthetic disease-modifying antirheumatic drug; FIL, filgotinib; LTE, long-term extension; MTX, methotrexate; NA, not applicable; PBO, placebo; RA, rheumatoid arthritis. }\end{array}$} \\
\hline
\end{tabular}




\section{Analysis sets}

The placebo-controlled safety analysis dataset included patients in four placebo-controlled trials randomised to filgotinib 200 or $100 \mathrm{mg}$ once a day or placebo up to 12 weeks (online supplemental figure S1). Treatment-emergent AEs (TEAEs) were defined as any $\mathrm{AE}$ with an onset date on or after the first dose of study drug and no later than the earliest date of either 30 days after the last dose of study drug or the first dose date of the switched treatment minus 1 day. Safety of filgotinib relative to active comparators adalimumab and methotrexate was reported by Combe et $a l^{4}$ and Westhovens et $a l^{5}$ and is not presented as part of this analysis.

The long-term, as-treated analysis dataset included all available data from patients in all seven trials who received $\geq 1$ dose of filgotinib 200 or $100 \mathrm{mg}$ once a day. Data were included from the original assigned treatment and after rerandomisation/reassignment to filgotinib. Therefore, patients may have contributed exposure time to more than one treatment group. Events were assigned to treatment received at time of event, with a 30-day window after last dose. The long-term, as-treated analysis dataset was the largest. It included patients with the longest exposure and was used to describe long-term, exposure-adjusted incidence rates (EAIRs). Data are presented through 96 weeks; beyond 96 weeks, the numbers of events and the numbers of patients still exposed to study drug were small, rendering interpretation difficult.

Safety was assessed through TEAEs, TEAEs leading to treatment discontinuation, serious AEs (SAEs), deaths, AE severity, AESIs and laboratory abnormalities coded according to Medical Dictionary for Regulatory Activities.

AESIs included infections, serious infections, opportunistic infections (OIs), active TB, herpes zoster (HZ) reactivation, MACE, venous thromboembolism (VTE), arterial thrombotic events (ATE; not including stroke or myocardial infarctions (MI)), malignancies, non-melanoma skin cancers (NMSC) and gastrointestinal perforation. Serious infections were infections meeting SAE criteria. Mucocutaneous candidiasis and superficial fungal infections were not considered OIs; TB and genital, disseminated and ophthalmic HZ were considered OIs. Herpes simplex virus (HSV) infection was also monitored. MACE, VTE and ATE positively adjudicated by an independent committee were included. MACE included cardiovascular (CV) death, MI and stroke, while ATEs were defined as all arterial events other than MI or stroke. VTE included pulmonary embolism and deep vein thrombosis (DVT). All deaths, including those that occurred off study drug, are reported.

\section{Statistical methods}

Baseline demographics and disease characteristics were summarised by descriptive statistics. For the placebo-controlled dataset, the proportion of patients with an event was described (n (\%)) during the 12-week, placebo-controlled period.

For each exposure-group in the as-treated dataset, filgotinib patient-years of exposure (PYE) were calculated as (last dose date - first dose date +1$) / 365.25$. If patients had multiple events, only the first event was counted. EAIRs per 100 PYE (100PYE) and 95\% CIs were calculated using Poisson regression model including treatment and study as covariates to account for different study sizes and log of PYE as offset. If a specific event was not observed in any study, data were integrated across all studies, and the Poisson regression model only included treatment without adjusting by study. If a specific event was not observed in a treatment after studies were integrated, crude EAIRs and their differences were calculated. For crude EAIRs, 95\% CIs were derived using an exact method ${ }^{9}$ and based on confidence limits of individual point estimates. ${ }^{10}$

\section{RESULTS}

\section{Patient population and exposure}

Demographics and disease characteristics at baseline were well balanced and similar across treatment groups. Nineteen percent of patients were aged $\geq 65$ years. At baseline, $91 \%$ and $88 \%$ of patients received csDMARDs concomitantly with treatment in the placebocontrolled and as-treated datasets; $39 \%$ and $38 \%$ of patients in the placebo-controlled and as-treated datasets received corticosteroids concomitantly with treatment (table 2). Across datasets, mean baseline Disease Activity Score with 28 joints using CRP was 5.7-5.9. Forty percent to $45 \%$ of patients had $\geq 1$ traditional CV risk factor.

The placebo-controlled dataset included 777,788 and 781 patients receiving filgotinib $200,100 \mathrm{mg}$ and placebo. In the as-treated dataset, 2267 patients received filgotinib $200 \mathrm{mg}$ for 4047.7 PYE, 1647 patients received filgotinib $100 \mathrm{mg}$ for 2032.9 PYE. Median filgotinib treatment duration was 1.6 years; 2740 $(74.2 \%)$ patients received treatment for $\geq 1$ year (table 3 ). As of the data cut-off, 16 September 2019, the longest individual exposure to filgotinib was up to 5.6 years.

\section{Overall AEs}

During the 12-week, placebo-controlled period, rates of TEAEs, grade $\geq 3$ TEAEs, serious TEAEs and TEAEs leading to study drug discontinuation were comparable for filgotinib and placebo (table 3). Most common TEAEs were nasopharyngitis, upper respiratory tract infection (URTI) and nausea (table 4). Most common TEAE leading to discontinuation was pneumonia $(\mathrm{n}=3(0.4 \%)$ filgotinib $200 \mathrm{mg}$, $\mathrm{n}=2(0.3 \%)$ filgotinib $100 \mathrm{mg}, \mathrm{n}=2(0.3 \%)$ placebo), followed by RA flare (among placebo patients only, $\mathrm{n}=5(0.6 \%)$ ) and gammaglutamyltransferase increased $(n=1(0.1 \%)$ filgotinib $200 \mathrm{mg}, \mathrm{n}=2$ $(0.3 \%)$ filgotinib $100 \mathrm{mg})$. EAIRs of grade $\geq 3$ TEAEs, SAEs and TEAEs leading to discontinuation were comparable between doses.

Twenty-five deaths were reported in filgotinib groups (table 3). During the placebo-controlled period, four patients died (figure 1A). Long-term, more deaths occurred in the filgotinib $200 \mathrm{mg}$ group than the $100 \mathrm{mg}$ group; EAIRs (95\% CI) of all deaths did not change over 96 weeks (figure 1B). Most deaths in the longterm analysis were due to CV events, serious infection, and malignancies (online supplemental table S1); all fatal MI $(n=2$; one each in filgotinib 200 and 100 groups) and strokes ( $n=3 ; 2$ with filgotinib 200 and 1 with filgotinib $100 \mathrm{mg}$ ) occurred in patients with $\geq 1 \mathrm{CV}$ risk factor. Acute DVT was the cause of death for one patient receiving filgotinib 200.

\section{AEs of special interest}

During the placebo-controlled period, infections were more frequent in both filgotinib groups versus placebo (figure 1C, table 3). Long-term, EAIRs of infections decreased over time (figure 1D). Overall, the most commonly reported infections were URTI, nasopharyngitis and urinary tract infection (UTI). EAIRs were similar between the two doses. During the placebocontrolled period, serious infections occurred in 20 patients (figure 1E). Long-term, EAIRs for serious infections did not vary over time (figure 1F). The most common serious infections were pneumonia, cellulitis and bronchitis; each occurred at similar rates between the filgotinib 200 and 100 groups.

Nine OIs were reported with filgotinib. No OIs or active TB occurred during the placebo-controlled period (table 3 ). Long term, EAIRs for OIs were $0.1(0.1-0.3)$ and $0.2(0.1-0.5) / 100$ PYE for filgotinib 200 and $100 \mathrm{mg}$. Active TB was reported in three patients receiving filgotinib $100 \mathrm{mg}$ from endemic areas (Hong Kong, Poland, India). 
Table 2 Baseline demographics, disease characteristics and cardiovascular risk factors

\begin{tabular}{|c|c|c|c|c|c|}
\hline & \multicolumn{3}{|c|}{ PBO controlled } & \multicolumn{2}{|c|}{ Long term, as-treated } \\
\hline & $\begin{array}{l}\text { FIL } 200 \mathrm{mg} \\
\mathrm{N}=777\end{array}$ & $\begin{array}{l}\mathrm{FIL} 100 \mathrm{mg} \\
\mathrm{N}=788\end{array}$ & $\begin{array}{l}\mathrm{PBO} \\
\mathrm{N}=781\end{array}$ & $\begin{array}{l}\text { FIL } 200 \mathrm{mg} \\
\mathrm{N}=2267\end{array}$ & $\begin{array}{l}\text { FIL } 100 \mathrm{mg} \\
\mathrm{N}=1647\end{array}$ \\
\hline Age, mean $\pm S D$ years & $53 \pm 12.6$ & $53 \pm 12.4$ & $54 \pm 12.6$ & $53 \pm 12.8$ & $53 \pm 12.8$ \\
\hline$\geq 65$ years & $135(17.4)$ & $151(19.2)$ & $158(20.2)$ & $410(18.1)$ & $327(19.9)$ \\
\hline$\geq 75$ years & $26(3.3)$ & $27(3.4)$ & $25(3.2)$ & $76(3.4)$ & $67(4.1)$ \\
\hline Female & $633(81.5)$ & $636(80.7)$ & $638(81.7)$ & $1828(80.6)$ & $1319(80.1)$ \\
\hline \multicolumn{6}{|l|}{ Race } \\
\hline Asian & $137(17.6)$ & $136(17.3)$ & $124(15.9)$ & $372(16.4)$ & $286(17.4)$ \\
\hline Black or African American & $21(2.7)$ & $20(2.5)$ & $35(4.5)$ & $63(2.8)$ & $53(3.2)$ \\
\hline White & $543(69.9)$ & $548(69.5)$ & $528(67.6)$ & $1568(69.2)$ & $1137(69.0)$ \\
\hline Other & $76(9.8)$ & $83(10.5)$ & $90(11.5)$ & $262(11.6)$ & $170(10.3)$ \\
\hline Hispanic or Latino & $151(19.4)$ & $169(21.4)$ & $173(22.2)$ & $525(23.2)$ & $355(21.6)$ \\
\hline $\mathrm{BMI}$, mean $\pm \mathrm{SD} \mathrm{kg} / \mathrm{m}^{2}$ & $27.6 \pm 6.25$ & $27.4 \pm 6.28$ & $27.7 \pm 6.28$ & $27.6 \pm 6.20$ & $27.6 \pm 6.20$ \\
\hline$\geq 25 \mathrm{~kg} / \mathrm{m}^{2}$ & $472(60.7)$ & $496(62.9)$ & $482(61.7)$ & $1402(61.8)$ & $1034(62.8)$ \\
\hline$\geq 30 \mathrm{~kg} / \mathrm{m}^{2}$ & $229(29.5)$ & $234(29.7)$ & $235(30.1)$ & $668(29.5)$ & $498(30.2)$ \\
\hline Duration of RA from diagnosis, mean \pm SD years & $8.6 \pm 8.2$ & $9.1 \pm 8.0$ & $8.6 \pm 8.1$ & $6.3 \pm 7.6$ & $7.4 \pm 7.8$ \\
\hline Range, years & $0.3-49.7$ & $0.1-41.8$ & $0.1-51.4$ & $0.0-52.3$ & $0.0-51.4$ \\
\hline hsCRP, mean \pm SD mg/L & $18.2 \pm 21.4$ & $19.3 \pm 25.9$ & $18.0 \pm 24.4$ & $18.9 \pm 24.5$ & $18.6 \pm 25.6$ \\
\hline DAS28 (CRP), mean \pm SD & $5.9 \pm 0.9$ & $5.8 \pm 1.0$ & $5.9 \pm 0.9$ & $5.8 \pm 0.9$ & $5.8 \pm 1.0$ \\
\hline $\mathrm{CDAl}$, mean $\pm \mathrm{SD}$ & $40.5 \pm 12.38$ & $39.9 \pm 12.59$ & $40.4 \pm 11.69$ & $40.4 \pm 12.26$ & $39.7 \pm 12.23$ \\
\hline $\mathrm{HAQ}-\mathrm{DI}$, mean $\pm \mathrm{SD}$ & $1.65 \pm 0.611$ & $1.61 \pm 0.637$ & $1.66 \pm 0.600$ & $1.62 \pm 0.623$ & $1.62 \pm 0.618$ \\
\hline Concurrent oral corticosteroids* & $300(38.6)$ & $305(38.7)$ & $297(38.0)$ & $781(34.5)$ & $631(38.3)$ \\
\hline Mean \pm SD mg/day & & & & $6.3 \pm 2.69$ & $6.3 \pm 2.57$ \\
\hline Concurrent csDMARDs* & $710(91.4)$ & $721(91.5)$ & $712(91.2)$ & $1843(81.3)$ & $1500(91.1)$ \\
\hline Concurrent MTX* & $685(88.2)$ & $692(87.8)$ & $678(86.8)$ & $1219(53.8)$ & $1100(66.8)$ \\
\hline Prior exposure to bDMARDs & $181(23.3)$ & $179(22.7)$ & $164(21.0)$ & $276(12.2)$ & $255(15.5)$ \\
\hline Concurrent oral contraceptive* & $51(6.6)$ & $53(6.7)$ & $31(4.0)$ & $127(5.7) \dagger$ & $97(6.1) \dagger$ \\
\hline Concurrent statin* & $68(8.8)$ & $95(12.1)$ & $93(11.9)$ & $213(9.4)$ & $186(11.3)$ \\
\hline \multicolumn{6}{|l|}{ Nicotine use $\ddagger$} \\
\hline Current & $84(13.5)$ & $95(15.0)$ & $88(14.1)$ & 244 & 193 \\
\hline Former & $85(13.7)$ & $81(12.8)$ & $80(12.8)$ & 236 & 174 \\
\hline Medical history & $310(39.9) \S$ & $349(44.3) \S$ & $331(42.4) \S$ & $950(41.9) \uparrow$ & $740(44.9)$ ๆ \\
\hline Diabetes $\neq$ & $76(12.2)$ & $61(9.6)$ & $69(11.1)$ & $221(9.7)$ & $158(9.6)$ \\
\hline Hypertension & $263(33.8)$ & $276(35.0)$ & $274(35.1)$ & $766(33.8)$ & $560(34.0)$ \\
\hline Dyslipidaemia & $118(15.2)$ & $130(16.5)$ & $147(18.8)$ & $336(14.8)$ & $280(17.0)$ \\
\hline CVD & $47(6.0)$ & $30(3.8)$ & $44(5.6)$ & $111(4.9)$ & $69(4.2)$ \\
\hline Ischaemic CNS vascular conditions & $17(2.2)$ & $17(2.2)$ & $19(2.4)$ & $51(2.2)$ & $34(2.1)$ \\
\hline Peripheral vascular disease & - & - & - & $5(0.2)$ & $6(0.4)$ \\
\hline DVT/PE & $6(0.8)$ & $7(0.9)$ & $11(1.4)$ & $18(0.8) t$ & $14(0.9) \dagger$ \\
\hline
\end{tabular}

Data are $\mathrm{n}(\%)$ unless otherwise indicated. DVT/PE were unadjudicated.

${ }^{*}$ On first dosing date in parent study.

tFor FIL $200 \mathrm{mg}$ and FIL $100 \mathrm{mg}, \mathrm{n}=2227$ and 1600 .

\#PBO-controlled group includes patients enrolled in phase 3 trials only. For FIL $200 \mathrm{mg}$, FIL $100 \mathrm{mg}$, and PBO, $\mathrm{n}=622,633$ and 623

$\S$ Excluding diabetes and peripheral vascular disease.

IExcluding DVT/PE.

bDMARD, biological DMARD; BMI, body mass index; CDAl, Clinical Disease Activity Index; CNS, central nervous system; CRP, C reactive protein; CsDMARD, conventional synthetic DMARD; CVD, cardiovascular disease; DAS28(CRP), Disease Activity

Score with 28 joints using CRP; DMARD, disease-modifying antirheumatic drug; DVT, deep vein thrombosis; FIL, filgotinib; HAQ-DI, Health Assessment Questionnaire Disability Index; hsCRP, high sensitivity CRP; MTX, methotrexate; PBO, placebo;

$\mathrm{PE}$, pulmonary embolism; RA, rheumatoid arthritis.

In the placebo-controlled period, HZ occurred in 5 patients (figure $1 \mathrm{G}$; table 3). Long term, EAIRs of $\mathrm{HZ}$ were higher for filgotinib 200 vs $100 \mathrm{mg}$ and remained stable over time (figure $1 \mathrm{H}$ ). EAIRs of $\mathrm{HZ}$ infection/reactivation were generally higher among Asian patients than among the overall population based on the long-term, as-treated analysis set (online supplemental figure S2). Most $\mathrm{HZ}$ infections were mild to moderate, monodermatomal or adjacent dermatomal and nonvisceral. Most patients recovered after treatment interruption and could continue treatment on recovery. Six SAEs of $\mathrm{HZ}$ were reported by five patients receiving filgotinib $200 \mathrm{mg}$ and one receiving filgotinib $100 \mathrm{mg}$. All six patients were aged $\geq 53$ years, four of six were of Asian descent, three of six were taking concomitant corticosteroids and methotrexate, while one of six was taking only concomitant corticosteroids; one of six was known to have been vaccinated against $\mathrm{HZ}$. All six were hospitalised for their $\mathrm{HZ}$ event, and all events resolved. One of these cases was cutaneous disseminated HZ in a patient receiving filgotinib $200 \mathrm{mg}$ who was hospitalised and discontinued from the study.

During the placebo-controlled period, four patients reported HSV (table 3). Long term, EAIRs of HSV were 0.6 (0.4-1.1) and $0.9(0.6-1.4) / 100$ PYE for filgotinib 200 and $100 \mathrm{mg}$.

During the placebo-controlled period, five patients reported MACE; patients who had MI or stroke all had $\geq 1 \mathrm{CV}$ risk factor (figure 1I; table 3). EAIRs of MACE for filgotinib 200 and $100 \mathrm{mg}$ remained stable over time (figure 1J). One ATE, a grade $4 \mathrm{SAE}$ of peripheral artery thrombosis, was reported in a 64-year-old patient with hypertension and body mass index of 29.7 who was receiving filgotinib $200 \mathrm{mg}$.

Nine patients experienced VTEs; none occurred in the placebo-controlled period (figure $1 \mathrm{~K}$; table 3 ). EAIRs remained stable over time (figure $1 \mathrm{~L}$ ). All patients reporting VTEs had $\geq 1$ traditional risk factor. 
Table 3 Exposure to study drug and rates of safety events

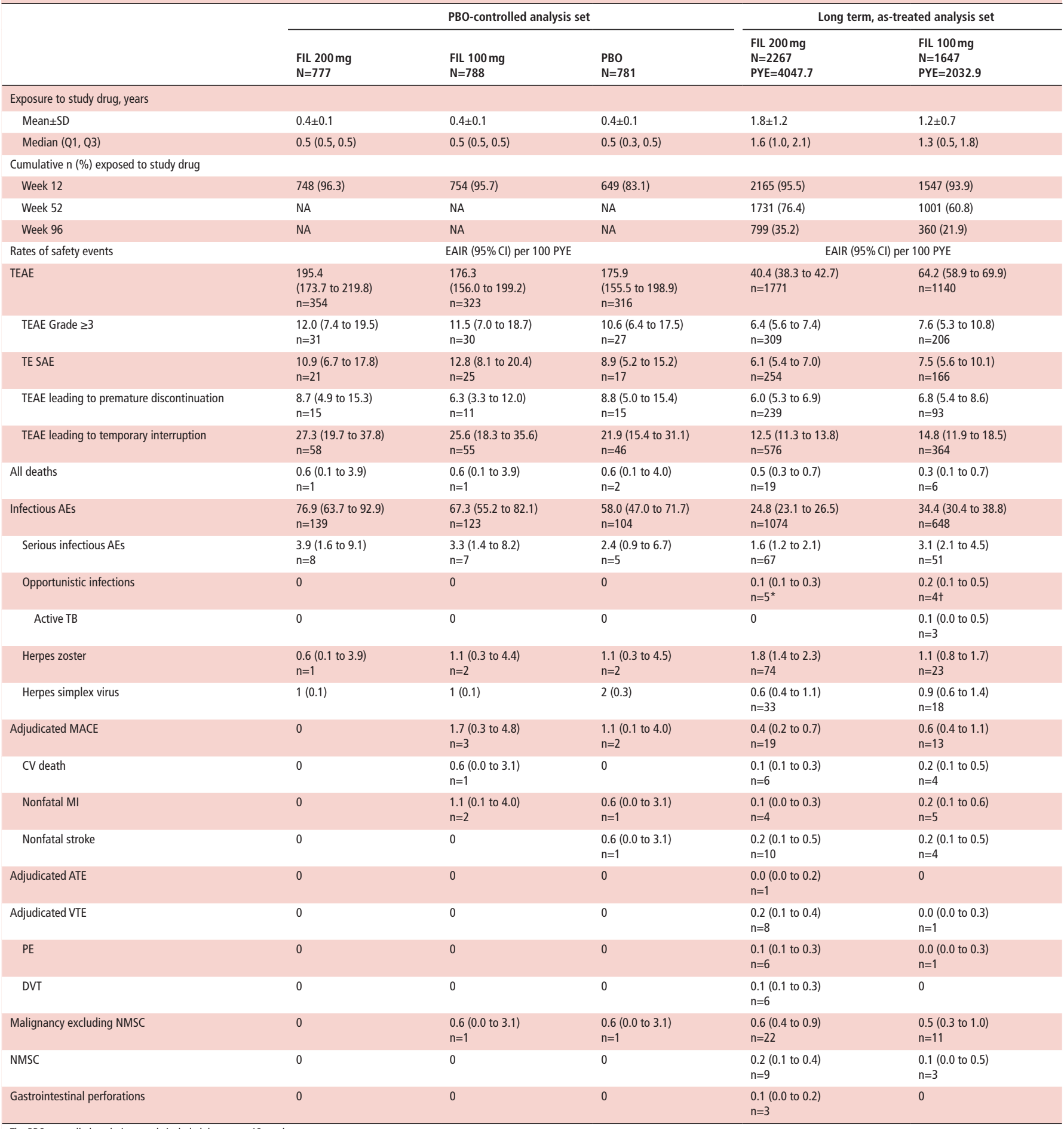

The PBO-controlled analysis set only included data up to 12 weeks.

*Two patients reported oesophageal candidiasis, one patient reported pneumonia cryptococcal, one patient reported herpes zoster disseminated and one patient reported both oesophageal candidiasis and pneumonia cryptococcal. tOne patient reported oesophageal candidiasis, one patient reported TB, one patient reported lymph node TB, one patient reported meningitis TB and one patient reported pulmonary TB.

AE, adverse event; ATE, arterial thrombotic event; CV, cardiovascular; DVT, deep vein thrombosis; EAIR, exposure-adjusted incidence rate; FIL, filgotinib; MACE, major adverse cardiovascular event; MI, myocardial infarction; NA, not applicable; NMSC, non-melanoma skin cancer; PBO, placebo; PE, pulmonary embolism; PYE, patient-years exposure; SAE, serious adverse event; $T B$, tuberculosis; TE, treatment-emergent; TEAE, treatment-emergent adverse event; VTE, venous thromboembolism.

During the placebo-controlled period, one malignancy each was reported with filgotinib $100 \mathrm{mg}$ (cervix carcinoma) and placebo (malignant glioma) (figure $1 \mathrm{M}$; table 3 ). Long term, EAIR of all non-NMSC malignancies for filgotinib 200 and $100 \mathrm{mg}$ remained stable over time (figure $1 \mathrm{~N}$ ). In patients receiving filgotinib $200 \mathrm{mg}$, one diffuse large B-cell lymphoma and three non-Hodgkin's lymphomas were reported; 1 T-cell lymphoma and one central nervous system lymphoma were reported with filgotinib $100 \mathrm{mg}$. During the placebo-controlled period, no NMSCs were reported (figure 1O, table 3). EAIRs for NMSC were $0.2(0.1-0.4)$ and $0.1(0-0.5) / 100$ PYE for filgotinib 200 and $100 \mathrm{mg}$ (figure 1P).

No gastrointestinal perforations occurred during the placebocontrolled period (table 3). Gastrointestinal perforations were reported for three patients receiving filgotinib $200 \mathrm{mg}$ with risk factors of concomitant non-steroidal anti-inflammatory (one 
Table 4 Common TEAEs ( $\geq 3 \%$ in any treatment group) in the PBO controlled period up to week 12

\begin{tabular}{llll}
\hline & $\begin{array}{lll}\text { FIL 200 mg } \\
\mathrm{N}=777\end{array}$ & $\begin{array}{l}\text { FIL 100 mg } \\
\mathrm{N}=788\end{array}$ & $\begin{array}{l}\text { PBO } \\
\mathrm{N}=781\end{array}$ \\
\hline Nasopharyngitis, $\mathrm{n}(\%)$ & $27(3.5)$ & $19(2.4)$ & $19(2.4)$ \\
Upper respiratory tract infection, $\mathrm{n}(\%)$ & $26(3.3)$ & $20(2.5)$ & $14(1.8)$ \\
Nausea, $\mathrm{n}(\%)$ & $27(3.5)$ & $18(2.3)$ & $13(1.7)$ \\
\hline
\end{tabular}

FIL, filgotinib; PBO, placebo; TEAE, treatment-emergent adverse event.

patient) and corticosteroid (one patient) use; EAIR was 0.1 (0-0.2)/100PYE.

Graded laboratory abnormalities occurring during the placebo-controlled period are reported in online supplemental table S2.

\section{DISCUSSION}

We evaluated the safety of filgotinib as treatment for RA with an integrated analysis encompassing seven trials that included 3691 patients, treated for a median of 1.6 years (maximum exposure, 5.6 years in $<3 \%$ of patients). In the placebo-controlled analysis dataset, proportions of patients with TEAEs, SAEs and AESIs were similar between those receiving filgotinib $200,100 \mathrm{mg}$ or placebo. The longterm, as-treated dataset revealed similar incidence between doses for most AESIs, with the exception of numeric differences in serious infection (higher incidence with filgotinib 100 vs $200 \mathrm{mg}$ ) and in VTE and HZ (higher incidence with filgotinib 200 vs $100 \mathrm{mg}$ ). Incidence of malignancy, MACE, and other serious events were similar between doses.

A numeric increase in mortality among the long-term, as-treated dataset was observed for filgotinib 200 (0.5/100PYE) vs $100 \mathrm{mg}$ (0.3/100PYE) and appeared to remain stable over time; however, rates were similar overall with overlapping CIs. Mortality rates were not adjusted for demographic factors or ageing over the study period, but they appear to fall within reported RA population rates and were consistent with those observed with other RA therapeutics. ${ }^{11-13}$ The leading causes of death for patients receiving filgotinib were those most frequently reported in patients with RA: CV death, infections and malignancies. ${ }^{12}{ }^{14-16}$ All fatal MI and strokes occurred in patients with $\geq 1 \mathrm{CV}$ risk factor. ${ }^{17}$

Patients with RA have increased risk for infection due to underlying disease and many of the immunosuppressive therapies used to treat it. ${ }^{18}$ Compared with csDMARDs, JAKi are associated with greater risk of serious infection, with observed incidence rates from RA clinical trials (generally 3-5/100PYE) similar between JAKi and biological DMARDs. ${ }^{19} 20$ The most common serious infections observed were those common among patients with RA (eg, pneumonia, skin and soft tissue infection, UTI). ${ }^{21}$ Though incidence of serious infection for the placebo-controlled dataset was $1.0 \%$ with filgotinib $200 \mathrm{mg}$ and $0.9 \%$ with filgotinib $100 \mathrm{mg}$, serious infection EAIRs were higher for filgotinib $100 \mathrm{mg}$ (3.1/100PYE) vs $200 \mathrm{mg}$ (1.6/100PYE). Overall infection rates decreased over time, while rates of serious infections appeared to remain stable. Though crosstrial comparisons are fraught with limitations and potential bias, the EAIR for serious infections with filgotinib $100 \mathrm{mg}$ was similar to those reported for other JAKi (including over LTE periods), which range from 2.7 to 6.2/100PYE, while the EAIR with filgotinib $200 \mathrm{mg}$ was slightly lower. ${ }^{1322-24}$ It is possible this lower EAIR with filgotinib $200 \mathrm{mg}$ may be explained, at least partially, by reduced inhibition of JAK2 and JAK3 relative to other JAKi. ${ }^{6}$

RA confers elevated risk for $\mathrm{HZ}$, and corticosteroids and JAKi can further increase this risk. ${ }^{25}$ Reactivation of latent varicella zoster virus by tofacitinib, baricitinib and upadacitinib has been described. ${ }^{13232426}$ From the placebo-controlled dataset, there were five cases of HZ: $1(0.1 \%)$ with filgotinib $200 \mathrm{mg}$ and $2(0.3 \%)$ with filgotinib $100 \mathrm{mg}$ and with placebo. For filgotinib 200 and $100 \mathrm{mg}$, EAIRs of HZ were 1.8 and 1.1/100PYE, and EAIRs were higher among Asian populations than among the overall population. As in other JAKi programmes, most $\mathrm{HZ}$ cases were monodermatomal and not serious. ${ }^{1324}$ Among the six patients who had SAEs of HZ, three were receiving concomitant corticosteroids and methotrexate, while one was receiving concomitant corticosteroid alone.

In the filgotinib programme, OIs-including active $\mathrm{TB}$-were infrequent; however, QF status was carefully monitored, and patients with changes in QF status discontinued the phase 2 LTE or had to pause study drug and start treatment for latent TB if applicable in the phase 3 LTE. Longer-term, real-world and populationbased data are needed to better understand the potential TB risk of filgotinib and other JAKi.

VTE risk is elevated for patients with RA compared with the general population ${ }^{27}{ }^{28}$; risk with JAKi is incompletely understood, ${ }^{29}{ }^{30}$ as is a potential mechanism for JAKi to cause VTE. Here, VTEs were infrequently reported (none from the placebo-controlled data set and EAIRs of 0.2/100PYE and 0.0/100PYE for filgotinib 200 and $100 \mathrm{mg}$ ), and their incidence did not increase over time. EAIR of VTEs was $0.5 / 100 \mathrm{PYE}$ for all doses in an integrated safety analysis of baricitinib ${ }^{22}$ and 0.6/100PYE for upadacitinib $15 \mathrm{mg}^{13}$ While real-world and population-based data are needed to better understand the potential risk of VTE associated with JAKi, our findings with filgotinib suggest a risk no greater than that reported from real-world studies showing background rates of VTE in RA of 0.3-1.0/100PYE. ${ }^{27} 28$

Patients with RA are also at increased risk for MACE compared with the general population. ${ }^{31} 32$ As expected, $40 \%-45 \%$ patients had a medical history of $\mathrm{CV}$ risk factors at baseline. MACE were infrequent, and EAIRs (0.4/100PYE and 0.6/100PYE for filgotinib 200 and $100 \mathrm{mg}$ ) remained stable over time.

Patients with RA experience higher rates of malignancies, due to underlying disease and immunosuppressive treatments, compared with the general population. ${ }^{33}$ In this analysis, malignancies were uncommon, and EAIRs did not increase with time exposed to filgotinib. Rates of malignancy excluding NMSC with filgotinib treatment $(0.6$ and 0.5/100PYE for filgotinib 200 and $100 \mathrm{mg})$ appeared to fall within the range reported from large registries of patients with RA. ${ }^{34}$ In integrated analyses of baricitinib and tofacitinib, EAIRs of malignancy excluding NMSC were 0.8 and 0.9/100PYE. ${ }^{22} 23$

Filgotinib was associated with decreases in mean neutrophil, lymphocyte and platelet counts and increases in mean lipid, CK and creatinine levels, as previously reported. ${ }^{1-5} 7$ There were small numerical differences in frequencies of Grade $3 / 4$ neutropenia and lymphopenia in patients treated with filgotinib versus placebo.

Limitations of this analysis include comparatively short follow-up for rare and long-latency events, especially malignancies. Relative to other JAKi, the filgotinib RA programme has included fewer patients. The short placebo-controlled period limited the assessment of filgotinib against the background of rare events, such as VTE. Filgotinib was also evaluated against active comparators for only 52 weeks. $^{45}$ The LTE trials did not have a control group, and clinicians were permitted to modify background therapy per clinical judgement, as they would in real-world treatment plans. Another limitation is survival bias: patients who had intolerable AEs or lack of efficacy were discontinued from their studies. Longerterm, adequately powered studies with greater numbers of patients and events are needed to better understand the safety of filgotinib, describe the incidence of uncommon events over time, and assess its safety relative to other JAKi.

AESI incidence is generally similar between filgotinib 200 and $100 \mathrm{mg}$. Serious infection risk is likely elevated with filgotinib vs 

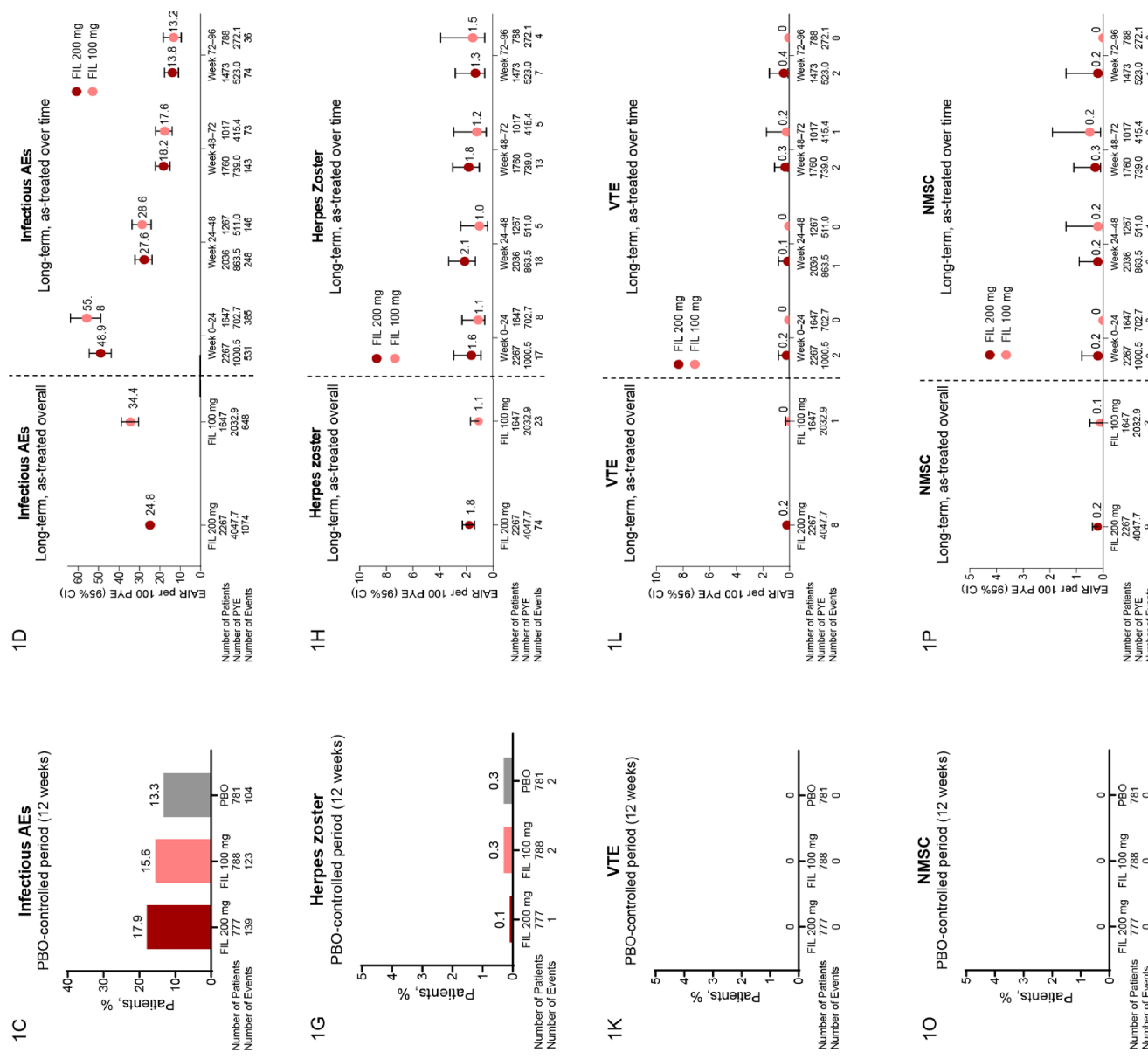

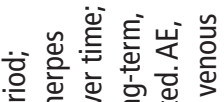

:

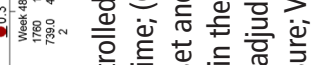

。ำ

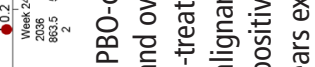

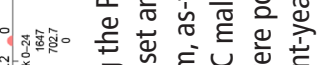

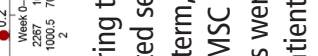

言密富住岁觉

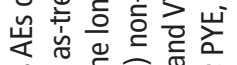

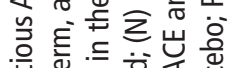

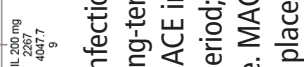

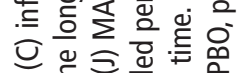

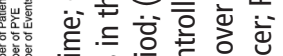

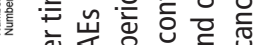

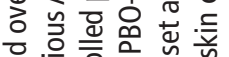

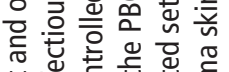

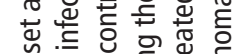
- 仓

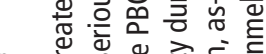

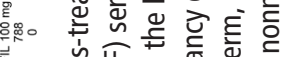

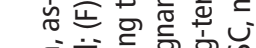

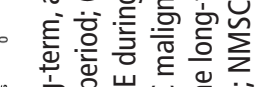

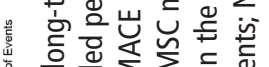

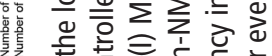

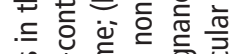

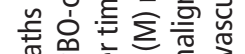
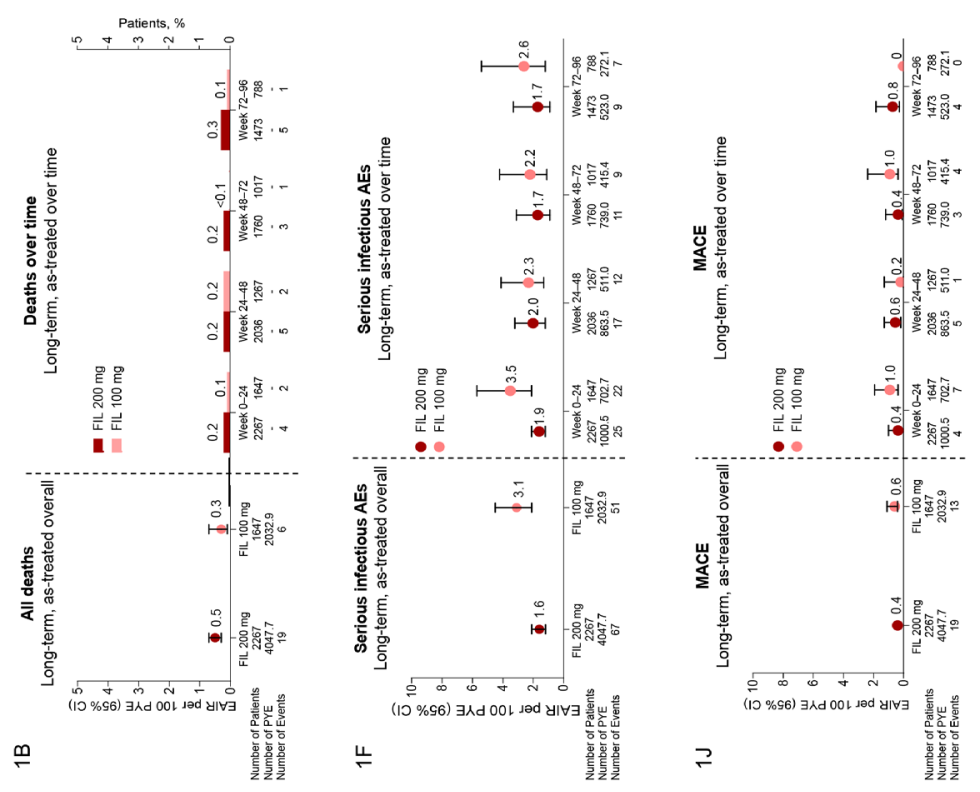
응

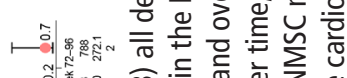

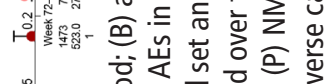

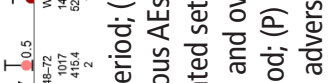

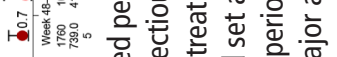

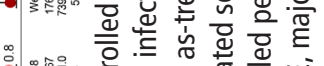

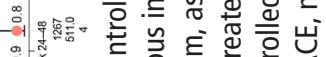

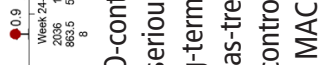

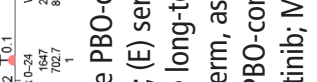

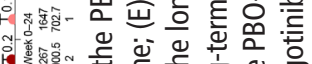

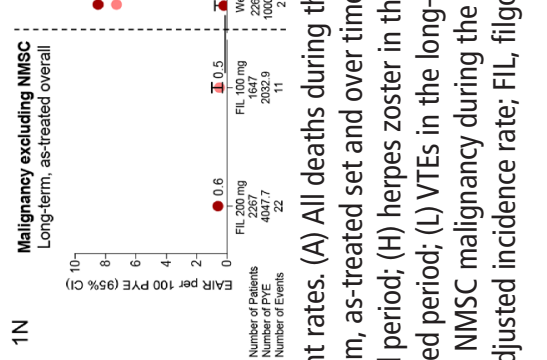

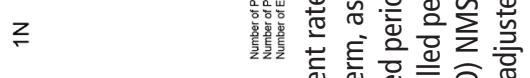

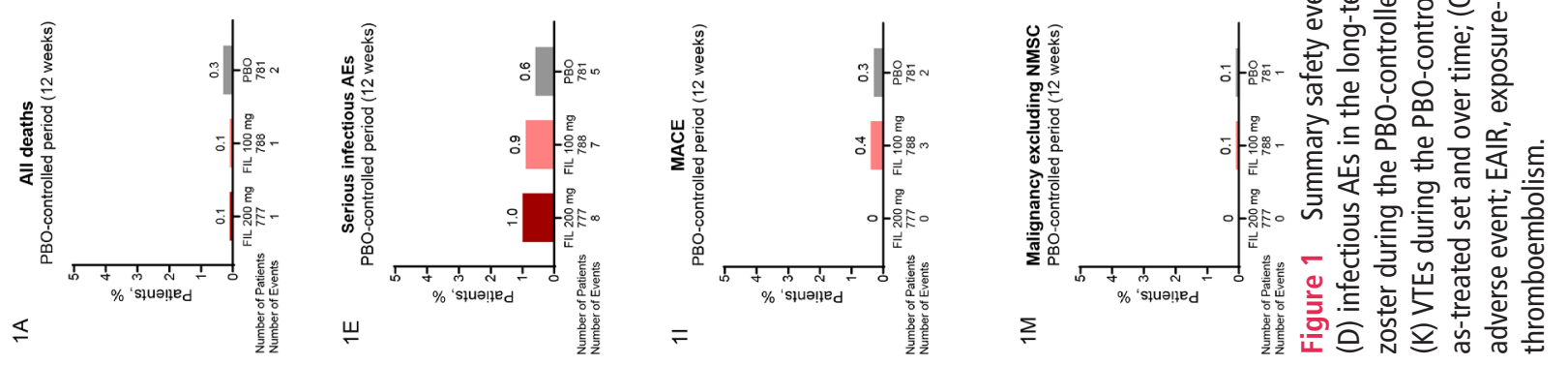


placebo, as is risk of HZ. Rates of VTE were low; malignancy and MACE were low and similar to that reported in population-based studies of RA. Over a median of 1.6 and maximum of 5.6 years of exposure, safety/tolerability of FIL200 and FIL100 were similar, with a lower incidence of infections with FIL200 among the longterm, as-treated dataset.

\author{
Author affiliations \\ ${ }^{1}$ Oregon Health \& Science University, Portland, Oregon, USA \\ ${ }^{2}$ The First Department of Internal Medicine, University of Occupational and \\ Environmental Health, Japan, Kitakyushu, Japan \\ ${ }^{3}$ Keio University School of Medicine, Shinjuku-ku, Tokyo, Japan \\ ${ }^{4}$ Altoona Research, Duncansville, Pennsylvania, USA \\ ${ }^{5}$ Gilead Sciences, Inc, Foster City, California, USA \\ ${ }^{6}$ Galapagos BV, Leiden, The Netherlands \\ ${ }^{7}$ Charité University Hospital Berlin, Berlin, Germany \\ ${ }^{8}$ Strasbourg University Hospital, Strasbourg, France
}

Acknowledgements Medical writing support was provided by Kathleen Pieper, PhD, and Gregory Bezkorovainy, MA, of AlphaScientia, LLC, and funded by Gilead Sciences, Inc.

Contributors All authors contributed to acquisition, analysis, or interpretation of data; had full access to the data; reviewed the manuscript critically for important intellectual content; and approved the final version for publication.

Funding Funding for DARWIN 1 and 2 was provided by Galapagos NV, and funding for DARWIN 3 and FINCH 1, 2, 3, and 4 was provided by Gilead Sciences, Inc. Funding for this analysis was provided by Gilead Sciences, Inc.

Competing interests KLW reports receiving grant/research support from AbbVie, Bristol Myers Squibb, and Pfizer and serving as a consultant for AbbVie, Bristol Myers Squibb, Eli Lilly and Co., Galapagos NV, Gilead Sciences, Inc., GlaxoSmithKline, Pfizer, Roche, Regeneron, Sanofi, and UCB. YT has received speaking fees and/or honoraria from Daiichi Sankyo, Eli Lilly, Novartis, YL Biologics, Bristol Myers, Eisai, Chugai, AbbVie, Astellas, Pfizer, Sanofi, Asahi-kasei, GSK, Mitsubishi-Tanabe, Gilead Sciences, Inc., Janssen; research grants from AbbVie, Mitsubishi-Tanabe, Chugai, Asahi Kasei, Eisai, Takeda, Daiichi Sankyo; and consultant fees from Eli Lilly, Daiichi Sankyo, Taisho, Ayumi, Sanofi, GSK, and AbbVie. TT reports receiving grant/research support from AbbVie, Asahi Kasei, Astellas, Chugai, Daiichi Sankyo, Eisai, Mitsubishi-Tanabe, Shionogi, Takeda, and UCB Japan; serving as a consultant for Astellas, Chugai, and Eli Lilly Japan; and serving on a speaker's bureau for AbbVie, AYUMI, Bristol Myers Squibb, Chugai, Daiichi Sankyo, Eisai, Eli Lilly Japan, Gilead Sciences, Inc., MitsubishiTanabe, Novartis, Pfizer Japan, Sanofi, and Dainippon Sumitomo. AK is a shareholder of Gilead Sciences, Inc., GlaxoSmithKline, Novartis, Pfizer, and Sanofi; serving as a consultant or advisor for AbbVie, Boehringer Ingelheim, Flexion, Genzyme, Gilead Sciences, Inc., Janssen, Novartis, Pfizer, Regeneron, Sanofi, and SUN Pharma Advanced Research; serving as a paid instructor for Celgene, Genzyme, Horizon, Merck, Novartis, Pfizer, Regeneron, and Sanofi; and serving on a speaker's bureau for AbbVie, Celgene, Flexion, Genzyme, Horizon, Lilly, Merck, Novartis, Pfizer, Regeneron, and Sanofi. FM, DJ, KC, and BB are employees and shareholders of Gilead Sciences, Inc. AJ is an employee of Novartis, a former employee of Gilead Sciences, Inc., and a shareholder of Gilead Sciences, Inc., Novartis, and Roche. MCG is a shareholder and employee of Gilead Sciences, Inc. and has received honoraria or consulting fees from AbbVie, Amgen, Beigene, Genentech, Gilead Sciences, Inc., Lilly Pharmaceuticals, Sanofi Genzyme, RPharm, and SetPoint. RB is a shareholder and employee of Galapagos. GRB reports serving as a consultant and on a speaker's bureau for AbbVie, Eli Lilly and Co., Galapagos, Gilead Sciences, Inc., and Pfizer. J-EG reports receiving grant/research support from Bristol Myers Squibb and Pfizer; serving as a consultant to AbbVie, Bristol Myers Squibb, Galapagos, Gilead Sciences, Inc., Pfizer, Eli Lilly and Co., and Sanofi Genzyme; and serving on a speaker's bureau for AbbVie, Eli Lilly and Co., Roche, Sanofi Genzyme, and UCB.

Patient consent for publication Not applicable.

Ethics approval The trials were conducted in accordance with the Declaration of Helsinki and the International Council for Harmonisation guidelines. The protocols were approved by the institutional review board or ethics committee at each site.

Provenance and peer review Not commissioned; externally peer reviewed.

Data availability statement Data are available on reasonable request. Anonymised individual patient data will be shared upon request for research purposes dependent upon the nature of the request, the merit of the proposed research, the availability of the data, and its intended use. The full data sharing policy for Gilead Sciences, Inc., can be found at https://www.gilead.com/scienceand-medicine/research/clinical-trials-transparencyand-data-sharing-policy.

Supplemental material This content has been supplied by the author(s). It has not been vetted by BMJ Publishing Group Limited (BMJ) and may not have been peer-reviewed. Any opinions or recommendations discussed are solely those of the author(s) and are not endorsed by BMJ. BMJ disclaims all liability and responsibility arising from any reliance placed on the content. Where the content includes any translated material, BMJ does not warrant the accuracy and reliability of the translations (including but not limited to local regulations, clinical guidelines, terminology, drug names and drug dosages), and is not responsible for any error and/or omissions arising from translation and adaptation or otherwise.

Open access This is an open access article distributed in accordance with the Creative Commons Attribution Non Commercial (CC BY-NC 4.0) license, which permits others to distribute, remix, adapt, build upon this work non-commercially, and license their derivative works on different terms, provided the original work is properly cited, appropriate credit is given, any changes made indicated, and the use is non-commercial. See: http://creativecommons.org/licenses/by-nc/4.0/.

\section{ORCID iDs}

Kevin L Winthrop http://orcid.org/0000-0002-3892-6947

Yoshiya Tanaka http://orcid.org/0000-0002-0807-7139

Tsutomu Takeuchi http://orcid.org/0000-0003-1111-8218

Mark C Genovese http://orcid.org/0000-0001-5294-4503

Gerd R Burmester http://orcid.org/0000-0001-7518-1131

Jacques-Eric Gottenberg http://orcid.org/0000-0002-9469-946X

\section{REFERENCES}

1 Westhovens R, Taylor PC, Alten R, et al. Filgotinib (GLPG0634/GS-6034), an oral JAK1 selective inhibitor, is effective in combination with methotrexate (MTX) in patients with active rheumatoid arthritis and insufficient response to MTX: results from a randomised, dose-finding study (DARWIN 1). Ann Rheum Dis 2017;76:998-1008.

2 Kavanaugh A, Kremer J, Ponce L, et al. Filgotinib (GLPG0634/GS-6034), an oral selective JAK1 inhibitor, is effective as monotherapy in patients with active rheumatoid arthritis: results from a randomised, dose-finding study (DARWIN 2). Ann Rheum Dis 2017;76:1009-19.

3 Genovese MC, Kalunian K, Gottenberg J-E, et al. Effect of filgotinib vs placebo on clinical response in patients with moderate to severe rheumatoid arthritis refractory to disease-modifying antirheumatic drug therapy: the FINCH 2 randomized clinical trial. JAMA 2019:322:315-25.

4 Combe B, Kivitz A, Tanaka Y, et al. Filgotinib versus placebo or adalimumab in patients with rheumatoid arthritis and inadequate response to methotrexate: a phase III randomised clinical trial. Ann Rheum Dis 2021;80:848-58.

5 Westhovens R, Rigby WFC, van der Heijde D, et al. Filgotinib in combination with methotrexate or as monotherapy versus methotrexate monotherapy in patients with active rheumatoid arthritis and limited or no prior exposure to methotrexate: the phase 3, randomised controlled FINCH 3 trial. Ann Rheum Dis 2021;80:727-38.

6 Traves PG, Murray B, Campigotto F, et al. JAK selectivity and the implications for clinical inhibition of pharmacodynamic cytokine signalling by filgotinib, upadacitinib, tofacitinib and baricitinib. Ann Rheum Dis 2021;80:865-75.

7 Kavanaugh A, Westhovens RR, Winthrop KL, et al. Safety and efficacy of filgotinib: up to 4-year results from an open-label extension study of phase II rheumatoid arthritis programs. J Rheumatol 2021;48:1230-8.

8 Aletaha D, Neogi T, Silman AJ, et al. 2010 rheumatoid arthritis classification criteria: an American College of Rheumatology/European League against rheumatism collaborative initiative. Arthritis Rheum 2010;62:2569-81.

9 UIm K. A simple method to calculate the confidence interval of a standardized mortality ratio (SMR). Am J Epidemiol 1990;131:373-5.

10 Li H-Q, Tang M-L, Poon W-Y. Confidence intervals for difference between two Poisson rates. Commun Stat Simul Comput 2011:40:1478-93.

11 Dadoun S, Zeboulon-Ktorza N, Combescure C, et al. Mortality in rheumatoid arthritis over the last fifty years: systematic review and meta-analysis. Joint Bone Spine 2013;80:29-33.

12 Widdifield J, Paterson JM, Huang A, et al. Causes of death in rheumatoid arthritis: how do they compare to the general population? Arthritis Care Res 2018;70:1748-55.

13 Cohen SB, van Vollenhoven RF, Winthrop KL. Correction: Safety profile of upadacitinib in rheumatoid arthritis: integrated analysis from the SELECT phase III clinical programme. Ann Rheum Dis 2021;80:304-11.

14 Cohen S, Radominski SC, Gomez-Reino JJ, et al. Analysis of infections and all-cause mortality in phase II, phase III, and long-term extension studies of tofacitinib in patients with rheumatoid arthritis. Arthritis Rheumatol 2014;66:2924-37.

15 van den Hoek J, Boshuizen HC, Roorda LD, et al. Mortality in patients with rheumatoid arthritis: a 15-year prospective cohort study. Rheumatol Int 2017;37:487-93.

16 Sparks JA, Chang S-C, Liao KP, et al. Rheumatoid arthritis and mortality among women during 36 years of prospective follow-up: results from the nurses' health study. Arthritis Care Res 2016;68:753-62.

17 Charles-Schoeman C, Bae S, Chopra A. Adjudicated MACE and VTE in the filgotinib RA program: integrated analysis from Phase 2 and 3 clinical trials [abstract]. Arthritis Rheumatol 2020;72.

18 Widdifield J, Bernatsky S, Paterson JM, et al. Serious infections in a populationbased cohort of 86,039 seniors with rheumatoid arthritis. Arthritis Care Res 2013;65:353-61. 
19 Singh JA, Cameron C, Noorbaloochi S, et al. Risk of serious infection in biological treatment of patients with rheumatoid arthritis: a systematic review and metaanalysis. Lancet 2015;386:258-65.

20 Strand V, Ahadieh S, French J, et al. Systematic review and meta-analysis of serious infections with tofacitinib and biologic disease-modifying antirheumatic drug treatment in rheumatoid arthritis clinical trials. Arthritis Res Ther 2015;17:362.

21 Mehta B, Pedro S, Ozen G, et al. Serious infection risk in rheumatoid arthritis compared with non-inflammatory rheumatic and musculoskeletal diseases: a US national cohort study. RMD Open 2019;5:e000935.

22 Smolen JS, Genovese MC, Takeuchi T, et al. Safety profile of baricitinib in patients with active rheumatoid arthritis with over 2 years median time in treatment. J Rheumatol 2019;46:7-18.

23 Cohen SB, Tanaka Y, Mariette X, et al. Long-term safety of tofacitinib for the treatment of rheumatoid arthritis up to 8.5 years: integrated analysis of data from the global clinical trials. Ann Rheum Dis 2017;76:1253-62.

24 Winthrop KL, Harigai M, Genovese MC, et al. Infections in baricitinib clinical trials for patients with active rheumatoid arthritis. Ann Rheum Dis 2020:79:1290-7.

25 Smitten AL, Choi HK, Hochberg MC, et al. The risk of herpes zoster in patients with rheumatoid arthritis in the United States and the United Kingdom. Arthritis Rheum 2007;57:1431-8.

26 Winthrop KL, Melmed GY, Vermeire S, et al. Herpes zoster infection in patients with ulcerative colitis receiving tofacitinib. Inflamm Bowel Dis 2018;24:2258-65.
27 Holmqvist ME, Neovius M, Eriksson J, et al. Risk of venous thromboembolism in patients with rheumatoid arthritis and association with disease duration and hospitalization. JAMA 2012;308:1350-6.

28 Kim SC, Schneeweiss S, Liu J, et al. Risk of venous thromboembolism in patients with rheumatoid arthritis. Arthritis Care Res 2013;65:NA-7.

29 Pfizer. Pfizer announces modification to ongoing tofacitinib FDA post-marketing requirement study in patients with rheumatoid arthritis, news release, 2019.

30 Mease $\mathrm{P}_{1}$ Charles-Schoeman C, Cohen S, et al. Incidence of venous and arterial thromboembolic events reported in the tofacitinib rheumatoid arthritis, psoriasis and psoriatic arthritis development programmes and from real-world data. Ann Rheum Dis 2020;79:1400-13.

31 Ogdie A, Yu Y, Haynes K, et al. Risk of major cardiovascular events in patients with psoriatic arthritis, psoriasis and rheumatoid arthritis: a population-based cohort study. Ann Rheum Dis 2015;74:326-32.

32 Schieir O, Tosevski C, Glazier RH, et al. Incident myocardial infarction associated with major types of arthritis in the general population: a systematic review and metaanalysis. Ann Rheum Dis 2017:76:1396-404.

33 Simon TA, Thompson A, Gandhi KK, et al. Incidence of malignancy in adult patients with rheumatoid arthritis: a meta-analysis. Arthritis Res Ther 2015;17:212.

34 Askling J, Berglind N, Franzen S, et al. How comparable are rates of malignancies in patients with rheumatoid arthritis across the world? A comparison of cancer rates, and means to optimise their comparability, in five RA registries. Ann Rheum Dis 2016;75:1789-96 